\section{ORIGINAL RESEARCH}

\author{
P. Jun \\ N.U. Ko \\ J.D. English \\ C.F. Dowd \\ V.V. Halbach \\ R.T. Higashida \\ M.T. Lawton \\ S.W. Hetts
}

\title{
Endovascular Treatment of Medically Refractory Cerebral Vasospasm Following Aneurysmal Subarachnoid Hemorrhage
}

\author{
BACKGROUND AND PURPOSE: CV following aneurysmal SAH is a significant cause of morbidity and \\ mortality. We review our experiences using PTA and IA verapamil infusion for treating medically \\ refractory cases.
}

\begin{abstract}
MATERIALS AND METHODS: We performed a retrospective review of patients with SAH admitted from
\end{abstract} July 2003 to January 2008

\begin{abstract}
RESULTS: Of 546 patients admitted within 72 hours of symptom onset, 231 patients (42\%) developed symptomatic CV and 189 patients (35\%) required endovascular therapy. A total of 346 endovascular sessions were performed consisting of 1 single angioplasty, 286 IA verapamil infusions, and 59 combined treatments. PTA was performed on 151 vessel segments, and IA verapamil was infused in 720 vessel segments. IA verapamil doses ranged from 2.0 to $30.0 \mathrm{mg}$ per vessel segment and from 3.0 to $55.0 \mathrm{mg}$ per treatment session. Repeat treatments were necessary in 102 patients (54\%) for persistent, recurrent, or worsening CV. There were 6 treatment-related complications, of which 2 resulted in clinical worsening. No deaths were attributable to endovascular therapy. At follow-up, 115 patients $(61 \%)$ had a good outcome and 55 patients (29\%) had a poor outcome. Sixteen patients died from causes related to SAH, while 3 died from other medical complications.
\end{abstract}

CONCLUSIONS: Endovascular treatments are an integral part of managing patients with medically refractory CV. In our experience, PTA and IA verapamil are safe, with a low complication rate, but further studies are required to determine appropriate patient selection and treatment efficacy.

\begin{abstract}
ABBREVIATIONS: $\mathrm{ACA}=$ anterior cerebral artery; $\mathrm{CBF}=$ cerebral blood flow; $\mathrm{CCA}=$ common carotid artery; $\mathrm{CV}=$ cerebral vasospasm; DSA = digital subtraction angiogram; $\mathrm{HH}=$ Hunt and Hess scale; IA = intra-arterial; ICA = internal carotid artery; ICP = intracranial pressure; ISAT = International Subarachnoid Aneurysm Trial; $\mathrm{MCA}=$ middle cerebral artery; $\mathrm{mRS}=$ modified Rankin Scale; PCA = posterior cerebral artery; PTA = percutaneous transluminal angioplasty; SAH = subarachnoid hemorrhage; TCD = transcranial Doppler; UCSF = University of California, San Francisco
\end{abstract}

C $\mathrm{V}$ following aneurysmal SAH is a leading cause of morbidity and mortality. ${ }^{1}$ Intracranial arterial narrowing and impaired cerebral autoregulation can reduce $\mathrm{CBF}$ and cause signs of ischemia as early as 72 hours after aneurysm rupture..$^{2-5}$ Noninvasive medical measures to restore CBF are centered on hyperdynamic therapy, which consists of hypertension, hemodilution, and hypervolemia. ${ }^{6}$ However, not all patients can tolerate this treatment, and of those who can, $\leq 20 \%$ still develop CV severe enough to cause infarction and/or death. ${ }^{7,8}$

In these medically refractory cases, endovascular treatment provides an invasive therapeutic option. PTA and IA vasodilator infusion are the current modes of treatment. PTA is effective at expanding the luminal caliber, increasing CBF, and improving neurologic function. ${ }^{9-13}$ However, PTA is limited to $\mathrm{CV}$ of the proximal large arteries at the base of the brain and has a reported $2 \%-5 \%$ risk of stroke or death. ${ }^{14}$ The data sur-

Received February 14, 2010; accepted after revision April 18.

From the Departments of Radiology (P.J., J.D.E., C.F.D., V.V.H., R.T.H., S.W.H.), Neurology (N.U.K., J.D.E.) and Neurosurgery (M.T.L.), University of California, San Francisco, California.

Previously presented in part at: 41 st Annual Meeting of the Western Neuroradiological Society, October 8-11, 2009; Napa, California.

Please address correspondence to Steven W. Hetts, MD, Department of Radiology, University of California, 505 Parnassus Ave, L-352, San Francisco, CA 94143-0628; e-mail: steven.hetts@radiology.ucsf.edu

DOI 10.3174/ajnr.A2183 rounding IA vasodilator infusions are less established. Most experience is with papaverine, which has questionable clinical benefits and has significant side effects. ${ }^{11,15,16}$ As a result, a shift toward calcium channel antagonists has emerged, with early reports showing angiographic response and clinical improvement with a better safety profile than either PTA or papaverine. ${ }^{17}$

At UCSF Medical Center, we use PTA and IA verapamil to treat medically refractory CV. Verapamil was chosen over other calcium channel antagonists because it has a long and safe history for treating coronary vasospasm. ${ }^{18}$ Our philosophy for treating medically refractory CV is that angiographically proved CV in a patient with ischemic symptoms warrants endovascular intervention. The purpose of this study was to describe our recent experience using endovascular treatments in this patient population.

\section{Materials and Methods}

\section{Patients}

A retrospective chart review was conducted from July 2003 to January 2008 of all patients with aneurysmal SAH confirmed by nonenhanced head CT or lumbar puncture admitted to the UCSF Medical Center within 72 hours of symptom onset. Patients who presented to or were transferred to UCSF Medical Center $>72$ hours into their course of $\mathrm{SAH}$ were excluded from this analysis due to presumed greater het- 
erogeneity of initial care at outside institutions or lack of care when presenting in a delayed fashion. We extracted the following data: patient age and sex, date of symptom onset, $\mathrm{HH}$ grade, ${ }^{19}$ Fisher scale,${ }^{20}$ aneurysm location and treatment, distribution and severity of the $\mathrm{CV}$, endovascular treatments and complications, and $\mathrm{mRS}^{21}$ at the latest follow-up. Approval from the institutional review board was obtained.

\section{Initial Patient Management}

All patients were admitted to the neurointensive care unit where they received standard SAH management, including oral nimodipine. A conventional 4-vessel DSA was performed to confirm the presence of an aneurysm and to serve as a baseline. Ruptured aneurysms were secured by surgical clips or endovascular coil exclusion. Frequent neurologic examinations and, when available, TCD sonograms were obtained. Patients were placed on hyperdynamic therapy when they developed new neurologic deficits not explained by other causes (rebleeding, hydrocephalus, seizures, infection, or metabolic disturbances). Patients with rising TCD velocities due to vasospasm were also placed on hyperdynamic therapy even if they had not yet developed focal neurologic deficits. The target systolic blood pressure for hyperdynamic therapy was $160 \mathrm{~mm} \mathrm{Hg}$ in normotensive patients and $180 \mathrm{~mm} \mathrm{Hg}$ in hypertensive patients. Those with persistent, worsening, or recurrent neurologic deficits or increasing TCD velocities and Lindegaard ratios after 12-24 hours or complications limiting hyperdynamic therapy, such as congestive heart failure or cerebral ischemia, were considered medically refractory and were taken to the neuroangiography suite for further evaluation.

\section{Endovascular Treatment}

An initial DSA was performed to confirm the presence of angiographic $\mathrm{CV}$ and determine its distribution. The supraclinoid ICA, M1 MCA, A1 ACA, intracranial vertebral artery, basilar artery, and P1 PCA were considered "proximal" vessels. Those beyond the above classification (eg, M2 MCA, A2 ACA, P2 PCA) were considered "distal" vessels in the sense that catheterization and PTA of these smaller vessels would likely have a higher than acceptable risk of vessel rupture, given their small size at baseline.

The severity of CV was determined by visually assessing the luminal narrowing compared with adjacent vessels and with the baseline DSA by experienced interventional neuroradiology attending physicians (C.F.D., V.V.H., R.T.H.). Mild CV was $<30 \%$, moderate CV was between $30 \%$ and $60 \%$, and severe CV was $>60 \%$ luminal narrowing. Patients were treated with PTA and/or IA verapamil at the discretion of the interventional neuroradiology attending physician. Generally, severe proximal CV was treated with PTA, and distal CV was treated with IA verapamil.

PTA was performed as previously described. ${ }^{12}$ Patients undergoing PTA were systemically anticoagulated by using intravenous heparin in a weight-based bolus dose (typically 4000-6000 U total) with a goal of doubling baseline activated clotting time. A guiding catheter was placed on heparinized saline drip in either the cervical ICA or cervical vertebral artery. Next, a low-compliance-tip occlusion balloon microcatheter (Sentry-10, Boston Scientific, Fremont, California or HyperGlide, ev3, Irvine, California) was navigated over a compatible 0.010 -inch microwire to the most distal aspect of the spastic vessel segment to be treated (ie, the smallest spastic arterial branch farthest from the femoral access site). Brief ( $<30$ seconds) and repeated inflation-deflation cycles $(\leq 5)$ with iodinated contrast material were performed to achieve at least $70 \%$ of the expected baseline vascular luminal diameter. The PTA catheter was then withdrawn prox- imally by $50 \%$ of the balloon length (eg, $5-\mathrm{mm}$ pull back for a $10-\mathrm{mm}$ length balloon), and this process was repeated as necessary to cover all the spastic arterial segments. Heparinization was reversed with protamine at the conclusion of the procedure.

IA verapamil infusion was performed by positioning the diagnostic catheter (5F UCSF2; Codman Neurovascular, Miami Lakes, Florida) in the proximal cervical ICA, the distal CCA (if vascular tortuosity or atherosclerotic stenosis precluded safe ICA catheterization), or the cervical vertebral artery proximal to the spastic vessel segment (eg, the ipsilateral ICA for treatment of distal vasospasm in the MCA or ACA). Verapamil was diluted in normal saline to a final concentration of $0.5 \mathrm{mg} / \mathrm{mL}$ and infused at a rate of $0.5 \mathrm{mg}$ per minute. For the few cases of isolated or particularly severe ACA or MCA vasospasm, a microcatheter (Prowler-14 LP ES, Codman Neurovascular or Excelsior SL-10, Boston Scientific) over a compatible 0.014-inch guidewire (Transend EX Platinum, Boston Scientific) was navigated to the A1 ACA, A2 ACA, or M1 MCA. Patients undergoing this microcatheterization were systemically heparinized in a manner similar to that in the patients undergoing PTA, with protamine reversal after microcatheter IA verapamil infusion. The dose of verapamil infused in each patient was determined by the catheter position and $\mathrm{CV}$ severity. Higher doses of verapamil were used in the less selective catheterizations (eg, CCA catheter position versus ICA catheter position) and in more severe CV.

Repeat DSA was performed to assess treatment response and complications in all patients immediately following PTA and either immediately or $\leq 30$ minutes following IA verapamil infusion. Although the vasodilatory effects of PTA are seen immediately, in our experience, the full vasodilatory effects of verapamil are not realized for 30 minutes to an hour following infusion, which has been corroborated in animal studies. ${ }^{22}$ We generally chose to minimize procedural time, thereby procedural risk, as opposed to waiting 30 minutes after verapamil infusion to angiographically confirm the full vasodilatory effect. In particularly severe cases of $\mathrm{CV}$, however, control angiograms were obtained after a 30-minute delay. All complications were recorded.

\section{Patient Outcome}

Patient outcome was measured by using the mRS at time of the last follow-up by a stroke neurologist, neurosurgeon, or interventional neuroradiologist. Outcome was considered good when the patient could perform the activities of daily living independently (mRS, $\leq 2$ ), while outcome was considered poor when the patient required assistance (mRS, 3-5). Causes of patient death (mRS, 6) were recorded.

\section{Statistical Analysis}

Data are presented by using descriptive statistics. For parametric data, we provide mean \pm SD. For nonparametric data, median and ranges are provided. A Kruskal-Wallis 1-way analysis of variance was used to determine whether there was a significant difference in the dose of verapamil infused, depending on CV severity. Post hoc testing was performed by using the Mann-Whitney $U$ test for pair-wise comparisons. A $\chi^{2}$ test was used to determine whether there was a significant difference in stratified patient outcomes. Significance was set at a $P$ value $<.05$.

\section{Results}

\section{Patient Characteristics}

During the study period, 546 patients were admitted to UCSF Medical Center for confirmed aneurysmal SAH within 72 


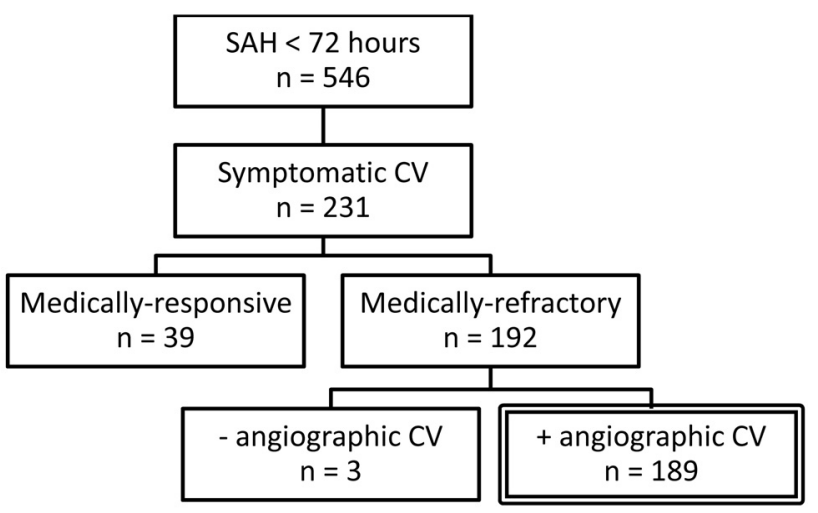

Fig 1. Selection of the study population from July 2003 to January 2008.

\begin{tabular}{|c|c|c|c|c|}
\hline & $\begin{array}{c}\text { Mild } \\
(n=90)\end{array}$ & $\begin{array}{l}\text { Moderate } \\
(n=138)\end{array}$ & $\begin{array}{c}\text { Severe } \\
(n=118)\end{array}$ & Total \\
\hline Proximal & 31 & 32 & 24 & 87 \\
\hline Distal & 27 & 24 & 11 & 62 \\
\hline Proximal + distal & 36 & 95 & 66 & 197 \\
\hline Total & 94 & 151 & 101 & 346 \\
\hline
\end{tabular}

Table 2: Distribution and frequency of PTA

\begin{tabular}{lc}
\hline Vessel Segment & Frequency $(n=151)$ \\
\hline M1 MCA & 57 \\
Supraclinoid ICA & 55 \\
Basilar artery & 17 \\
Vertebral artery & 11 \\
A1 ACA & 4 \\
P1 PCA & 4 \\
M2 MCA & 3 \\
\hline
\end{tabular}

hours of symptom onset. The final study population was selected as shown in Fig 1. There were 131 women (69\%). The mean age of all patients was $53 \pm 9$ years. The distribution of HH clinical grades was as follows: 43 patients (23\%) with grade 1, 36 patients (19\%) with grade 2, 58 patients $(31 \%)$ with grade 3, 36 patients (19\%) with grade 4 , and 16 patients (8\%) with grade 5 . The distribution of Fisher SAH grades was as follows: 1 patient $(0.5 \%)$ with grade 1,45 patients $(23.8 \%)$ with grade 2, 111 patients (58.8\%) with grade 3 , and $32 \mathrm{pa-}$ tients $(16.9 \%)$ with grade 4 . Eighty-four percent of ruptured aneurysms were in the anterior circulation. Surgical clip ligation was performed in 141 cases (75\%), and endovascular coil occlusion was performed in 48 cases (25\%).

\section{Endovascular Treatment}

The median time between symptom onset and endovascular treatment was 5 days (range, 2-13 days). The distribution and severity of medically refractory $\mathrm{CV}$ at the start of each treatment session is shown in Table 1. In total, 346 endovascular treatments were performed consisting of 1 case $(0.3 \%)$ of PTA, 286 cases (83\%) of IA verapamil infusion, and 59 cases (17\%) of combined PTA and verapamil infusion. PTA was performed on 151 vessel segments as shown in Table 2. All vessels were successfully dilated following PTA on posttreatment DSA. IA verapamil was infused in 720 vessel segments at a median dose as shown in Table 3. The dose of IA verapamil

\begin{tabular}{|c|c|c|}
\hline Vessel Segment & $\begin{array}{l}\text { Frequency } \\
(n=720)\end{array}$ & $\begin{array}{c}\text { Median Dose (mg) } \\
\text { (range) }\end{array}$ \\
\hline ICA & 536 & $10.0(2.0-30.0)$ \\
\hline Vertebral artery & 144 & $8.1(2.0-20.0)$ \\
\hline A1 ACA & 26 & $7.5(5.0-30.0)$ \\
\hline CCA & 8 & $15.0(5.0-15.0)$ \\
\hline M1 MCA & 4 & $10.0(10.0-10.0)$ \\
\hline A2 ACA & 1 & 10 \\
\hline Proatlantal artery & 1 & 5 \\
\hline
\end{tabular}

infused into the ICAs and vertebral arteries increased with worsening $\mathrm{CV}$ severity $(P<.05)$. Supra- and subselective infusions (ie, CCA, M1 MCA, and A1-A2 ACA) were excluded from this analysis for comparison purposes. The median total dose of verapamil infused per treatment session was $20.0 \mathrm{mg}$ (range, $3.0-55.0 \mathrm{mg}$ ).

Of the 189 patients, 87 (46\%) underwent a single treatment session, $63(33 \%)$ underwent 2 treatment sessions, 27 patients (14\%) underwent 3 treatment sessions, 8 (4\%) underwent 4 treatment sessions, and $4(2 \%)$ underwent 5 treatment sessions. Of the 346 treatment sessions performed, 157 (45\%) were repeated for persistent, worsening, or recurrent neurologic deficits. Repeat treatments were performed in $147 \mathrm{pa}-$ tients $(51 \%)$ treated with verapamil alone, $10(17 \%)$ treated with PTA and verapamil, and in no patients treated with PTA alone. The mean interval between treatments was $3 \pm 2$ days. On repeat DSA, the distribution and severity of CV improved in 52 cases, was unchanged in 28 cases, and worsened in 77 cases. Of note, only a single vessel required repeat PTA for recurrent $\mathrm{CV}$.

\section{Treatment-Related Complications}

There were 6 treatment-related complications in 189 patients (3.2\% per patient rate) during 349 treatment sessions (1.7\% per procedure rate). These occurred in different patients during separate treatments and included 3 vessel dissections, 1 vessel perforation, 1 intractable rise in ICP, and 1 thromboembolic event. None of these complications resulted in patient death; 2 intraprocedural complications (1.1\% per patient rate, $0.6 \%$ per procedure rate) resulted in clinical worsening. A single case of intractable ICP elevation occurred after the infusion of $12.5 \mathrm{mg}$ of verapamil into each ICA. Opening the extraventricular drain failed to relieve pressure, and the patient was taken for emergent decompressive craniectomy. Thromboembolism occurred in 1 case of PTA and was treated with intravenous abciximab infusion. The patient developed unilateral upper extremity weakness with a new infarct on CT. On 6-month follow-up examination, the patient had regained full strength in the extremity. Asymptomatic vascular dissections occurred in 2 cervical vertebral arteries and 1 cervical ICA as a result of catheterization. Stents were deployed in the vertebral arteries, and PTA was performed in the cervical ICA to restore flow. Asymptomatic intracranial arterial perforation occurred when a guidewire punctured the supraclinoid ICA. This was treated by reversal of heparinization and temporary balloon occlusion until resolution of contrast extravasation. There were no hemodynamic complications associated with verapamil infusion. 


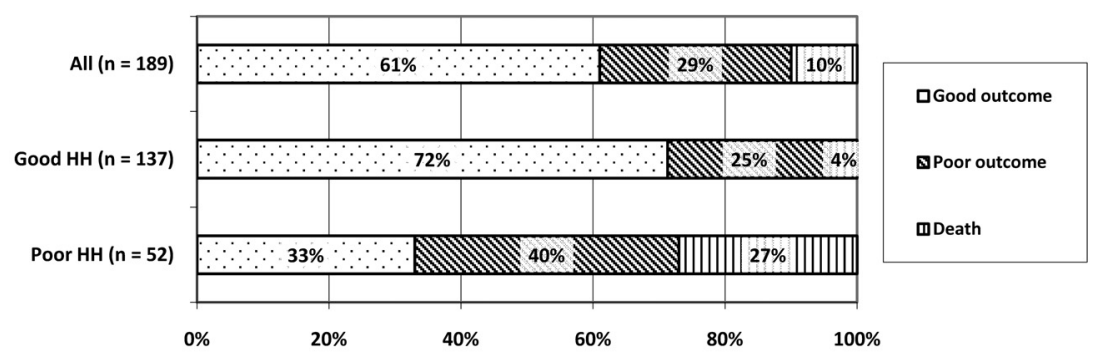

Fig 2. Longitudinal clinical outcomes. Differences between good (HH scores, 1-3) and poor (HH scores, 4 and 5) clinical presentation groups are significantly different for all outcome measures $\left(\chi^{2}=32, \mathrm{df}=2, P<.001\right)$.

\section{Clinical Outcome}

Longitudinal outcome data (Fig 2) were available for 153 patients (81\%) after a median of 180 days (range, 32-1637 days) following discharge. Thirty-six patients were lost to follow-up, and their discharge mRS score was used. In our study population, 115 patients $(61 \%)$ had a good outcome (mRS $\leq 2), 55$ patients $(29 \%)$ had a poor outcome (mRS 3-5), and 19 patients $(10 \%)$ died in the hospital. Patients were further stratified into 2 groups on the basis of their HH score. Of 137 patients $(72 \%)$ with a good clinical presentation ( $\mathrm{HH}$ scores, 1-3), 98 (72\%) had a good outcome, $34(25 \%)$ had a poor outcome, and $5(4 \%)$ died in the hospital. Of 52 patients (28\%) with a poor clinical presentation (HH scores, 4 and 5), $17(33 \%)$ had a good outcome, $21(40 \%)$ had a poor outcome, and $14(27 \%)$ died in the hospital. There was a significant difference in all clinical outcome measures between the stratified groups $\left(\chi^{2}, P<.001\right)$. Of the 19 patients who died, 16 died from causes related to their aneurysm rupture, while 3 died from other medical complications, including pneumonia, acute respiratory distress syndrome, and sepsis.

\section{Discussion}

This study examines our recent experience using PTA and IA verapamil to treat patients with aneurysmal SAH with medically refractory CV. We treated 189 patients during 349 treatment sessions, consisting of a single angioplasty, 286 IA verapamil infusions, and 59 combined therapies. In total, 151 vessel segments underwent PTA and 720 vessel segments were infused with verapamil. The procedural complication rate was $1.7 \%$ per procedure and $3.2 \%$ per patient. The clinically significant procedural complication rate was $0.6 \%$ per procedure and $1.1 \%$ per patient. Ultimately, $61 \%$ of patients had a good clinical outcome. To our knowledge, this constitutes the largest series of patients having undergone endovascular treatment for $\mathrm{CV}$ to date.

The goal of CV management is to prevent cerebral ischemia. Cerebral ischemia is likely a multifactorial process, but it is recognized that intracranial arterial luminal narrowing significantly reduces CBF. ${ }^{3,23-25}$ This relationship is explained by the Poiseuille equation, which states that flow is directly proportional to the pressure gradient and radius to the fourth power and inversely proportional to the fluid viscosity and vessel length. This forms the basis for a hyperdynamic therapy that tries to optimize the pressure gradient and fluid viscosity to improve CBF. ${ }^{26}$ However, there is a limit to how much these parameters can be modified before complications such as pulmonary edema, dilutional hyponatremia, and myocardial infarction occur. ${ }^{26,27}$ PTA and IA verapamil infusion are inva- sive options for restoring luminal caliber by mechanical or pharmaceutical means, respectively.

The choice of endovascular treatment is dictated by the distribution and severity of CV. PTA is limited to vessels that can safely accommodate the balloon microcatheter: the major cerebral arteries at the base of the brain and their most proximal branches. ${ }^{14}$ We further restricted the use of PTA to those vessels demonstrating severe CV. Because PTA has previously been reported to have a $2 \%-5 \%$ risk of stroke and death, ${ }^{14}$ we believe the risk-to-benefit ratio is minimized when only severe disease is treated. However, the performance characteristics of low-compliance balloon microcatheters have improved, and our own level of experience has increased significantly during the past 2 decades. Thus, our current complication rate from PTA (1.7\%, see the discussion below) is lower than that in an earlier series from our institution $(7.1 \%){ }^{12}$ In our current series, PTA was performed in 60 patients $(67 \%)$ of 90 in whom there was severe proximal or severe proximal and distal CV (Table 1). This rate implies that $33 \%$ of cases were either inaccessible or unfavorable for treatment by PTA. Examples include CV of the A1 segment, which is difficult to cannulate with a balloon microcatheter ${ }^{9,10,12,28,29}$ or which may be hypoplastic at baseline and thus not safe to balloon dilate. If no prior angiogram existed demonstrating that the A1 segment was not hypoplastic at baseline, then PTA of the Al segment was avoided. PTA of a vasospasm involving the vessel segment immediately adjacent to an aneurysm, which is associated with vessel rupture or surgical clip displacement, ${ }^{30}$ was also considered to be contraindicated.

In cases in which PTA could not be performed, we infused IA verapamil. Verapamil has been used for about 10 years to treat $\mathrm{CV}$, but optimal dosing remains in question. ${ }^{31-35} \mathrm{We}$ infused 2.0-30.0 mg per vessel segment. In our experience, these doses improved the luminal caliber in most cases; however, this finding cannot be confirmed on this retrospective study because delayed posttreatment DSA was not routinely performed in all patients. The efficacy of verapamil in improving the luminal caliber has been shown in earlier series: Feng et $\mathrm{al}^{32}$ found a $44 \%$ increase in vessel diameter following an average and maximum dose of 3 and $8 \mathrm{mg}$, respectively. Keuskamp et $\mathrm{al}^{33}$ showed a significant increase in vessel diameter in 10 of 12 patients who were given $\geq 20 \mathrm{mg}$ per vessel segment. Although Mazumdar et $\mathrm{al}^{34}$ failed to show a significant increase in vessel diameter after $2.5-10.0 \mathrm{mg}$ of verapamil, there was a trend to vasodilation in the most spastic vessels.

In our series, there was a direct correlation between the amount of verapamil infused and the severity of CV (Fig 3). 


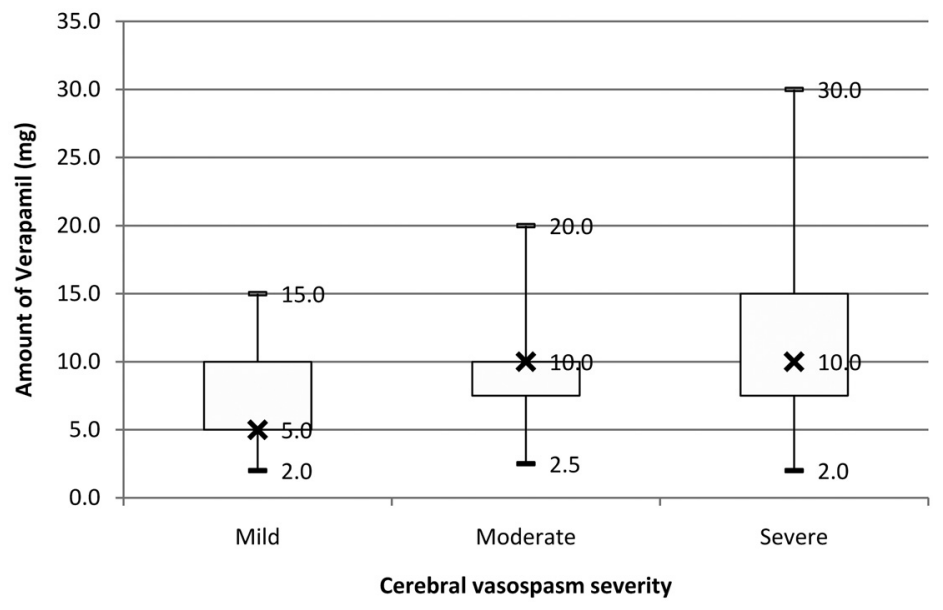

Fig 3. IA verapamil dose by CV severity. Only IA infusions into the ICA and vertebral arteries are considered ( $n=680$, $94 \%$ of total vessel segments infused). $X$ indicates the median verapamil dose.

Although this conclusion is intuitive and has been reported anecdotally in other studies, ${ }^{32}$ several confounding factors need to be considered. First, because CV severity was determined by visual inspection, there can be miscategorization, particularly in borderline cases. Second, even though our findings are statistically significant, they may not be clinically significant, given the wide overlap in doses between groups. Third, treatment bias is likely present because the amount of verapamil infused could be determined by operator experience rather than angiographic response. During the study period, all participating interventional neuroradiology attending physicians had 15-20 years of experience treating patients with SAH and CV. Finally, verapamil infusion is known to have an effect on spastic prearteriolar vessels, which are below the resolution of DSA. ${ }^{22}$ Functional measures such as CBF may thus be better end points for determining optimal verapamil dosing. ${ }^{4,24,36}$

There are limited data related to the durability of endovascular treatments. In our study, repeat treatments were performed in 102 patients (54\%); 17\% of cases treated with PTA and IA verapamil and $51 \%$ of cases treated with IA verapamil alone required repeat treatments. PTA had excellent durability in our series, with only a single vessel segment (2\%) requiring repeat PTA. This is in keeping with other series that have shown that vessel segments treated with angioplasty rarely restenose to the point of warranting further therapy. ${ }^{10,37}$ The durability of PTA has been explained by the ultrastructural changes that occur within the media of the mechanically dilated vessel wall. ${ }^{38,39}$

The length of therapeutic effect of IA verapamil in CV is not known. Although the biologic half-life of intravenous verapamil is 110 minutes, ${ }^{40}$ the persistence of its vasodilatory effect on the cerebral arteries is poorly understood. The coronary artery literature is not particularly instructive because coronary vasospasm tends to be much shorter lived (minutes) than CV (days to weeks). ${ }^{18}$ Whereas coronary vasospasm will resolve on its own in less than the half-life of verapamil, CV often persists well beyond the expected half-life of verapamil in the cerebral circulation. Thus, IA verapamil may have to be re-administered multiple times during a course of protracted $\mathrm{CV}$ to maintain $\mathrm{CBF}$ and prevent ischemia. The optimal time interval between IA verapamil infusions is not known, though most patients treated repeatedly with IA verapamil at our institution had a mean of 3 days in between. Prolonged IA verapamil infusion (for $\leq 20.5$ hours) with in-dwelling catheters has recently been described and provides a novel mode of administration. $^{31}$

Our recent experience demonstrates the safety of endovascular vasospasm therapy by using PTA and/or IA verapamil infusion. There were no treatment-related deaths, and of the 6 procedural complications, only 2 resulted in patient clinical deterioration. Distal embolization following PTA is a recognized complication and, in our patient, resulted in short-term disability with later full recovery. However, to our knowledge, intractable ICP elevation following IA verapamil has not been previously reported. Albanese et $\mathrm{al}^{31}$ described a single patient with transient ICP elevation during prolonged IA verapamil infusion that resolved on treatment cessation. Other studies have shown that IA verapamil has a negligible effect on ICP at similar or higher doses than that used to treat our patient. ${ }^{32-34}$ Although this case may represent refractory cerebral edema in a critically ill patient with $\mathrm{SAH}$, given its temporal relationship to IA verapamil infusion, vigilant ICP monitoring is warranted.

Although endovascular vasospasm therapies are safe, their efficacy remains poorly characterized. Both PTA and IA verapamil have been shown to improve neurologic status in the short term, but their long-term benefits remain inconclusive. In our series, $61 \%$ of patients had a good outcome, $29 \%$ had a poor outcome, and $10 \%$ died. Historically, mortality rates after SAH have been reported to be as high as $67 \%$ with up to a third requiring lifelong care. ${ }^{41}$ In the modern era, mortality and morbidity have steadily decreased and the ISAT reported the following outcomes after 1 year: $72 \%$ good, $18 \%$ poor, and $9 \%$ dead. ${ }^{42}$ However, the patient population of that trial differs significantly from the patient population in the current series. Specifically, ISAT included many patients who did not have medically refractory $\mathrm{CV}$, thus constituting a less morbid cohort than that presented our series. Thus, the outcomes in our tertiary care referral center may be similar, if not better, than other published clinical trials.

Ultimately, safety without efficacy is meaningless, and in the absence of efficacy, any patient risk is unwarranted. To our 
knowledge, there are no randomized studies of the effect of endovascular treatment for CV on outcomes. Small uncontrolled studies report a wide range of clinical improvement: $10 \%-80 \%{ }^{43}$ More rigorously controlled trials of CV therapies are, therefore, warranted. Given the current paradigm that $\mathrm{CV}$ causes ischemia and disabling infarction in $\leq 20 \%$ of patients with SAH, comparison of PTA and/or IA verapamil or other vasodilators with a pure placebo (ie, sham endovascular treatment) would be unethical. Trials comparing IA vasodilators of differing pharmacologic actions, such as verapamil and milrinone, would be an appropriate next step in the further elucidation of safe and efficacious prevention of $\mathrm{CV}$-induced cerebral infarction.

\section{Conclusions}

In summary, endovascular treatments are an integral part of managing patients with medically refractory CV. In our experience, endovascular vasospasm therapy is safe, with a low complication rate both for PTA and IA verapamil infusion. These data will serve as an impetus for further efficacy studies aimed at reducing the morbidity and mortality of patients with aneurysmal SAH.

\section{References}

1. Kassell NF, Torner JC, Haley EC Jr, et al. The International Cooperative Study on the Timing of Aneurysm Surgery. Part 1. Overall management results. J Neurosurg 1990;73:18-36

2. Yundt KD, Grubb RL Jr, Diringer MN, et al. Autoregulatory vasodilation of parenchymal vessels is impaired during cerebral vasospasm. J Cereb Blood Flow Metab 1998;18:419-24

3. Voldby B, Enevoldsen EM, Jensen FT. Regional CBF, intraventricular pressure, and cerebral metabolism in patients with ruptured intracranial aneurysms. J Neurosurg 1985;62:48-58

4. Ohkuma $\mathrm{H}$, Manabe $\mathrm{H}$, Tanaka $\mathrm{M}$, et al. Impact of cerebral microcirculatory changes on cerebral blood flow during cerebral vasospasm after aneurysmal subarachnoid hemorrhage. Stroke 2000;31:1621-27

5. Ishii R. Regional cerebral blood flow in patients with ruptured intracranial aneurysms. J Neurosurg 1979;50:587-94

6. Kassell NF, Sasaki T, Colohan AR, et al. Cerebral vasospasm following aneurysmal subarachnoid hemorrhage. Stroke 1985;16:562-72

7. Haley EC Jr, Kassell NF, Torner JC. The International Cooperative Study on the Timing of Aneurysm Surgery: the North American experience. Stroke 1992;23:205-14

8. Longstreth WT Jr, Nelson LM, Koepsell TD, et al. Clinical course of spontaneous subarachnoid hemorrhage: a population-based study in King County, Washington. Neurology 1993;43:712-18

9. Bejjani GK, Bank WO, Olan WJ, et al. The efficacy and safety of angioplasty for cerebral vasospasm after subarachnoid hemorrhage. Neurosurgery 1998;42: 979-86, discussion $986-87$

10. Eskridge JM, McAuliffe W, Song JK, et al. Balloon angioplasty for the treatment of vasospasm: results of first 50 cases. Neurosurgery 1998;42:510-16, discussion $516-17$

11. Firlik AD, Kaufmann AM, Jungreis CA, et al. Effect of transluminal angioplasty on cerebral blood flow in the management of symptomatic vasospasm following aneurysmal subarachnoid hemorrhage. J Neurosurg 1997;86:830-39

12. Higashida RT, Halbach VV, Dowd CF, et al. Intravascular balloon dilatation therapy for intracranial arterial vasospasm: patient selection, technique, and clinical results. Neurosurg Rev 1992;15:89-95

13. Polin RS, Coenen VA, Hansen CA, et al. Efficacy of transluminal angioplasty for the management of symptomatic cerebral vasospasm following aneurysmal subarachnoid hemorrhage. J Neurosurg 2000;92:284-90

14. Eskridge JM, Song JK. A practical approach to the treatment of vasospasm. AJNR Am J Neuroradiol 1997;18:1653-60

15. Mathis JM, DeNardo A, Jensen ME, et al. Transient neurologic events associated with intraarterial papaverine infusion for subarachnoid hemorrhageinduced vasospasm. AJNR Am J Neuroradiol 1994;15:1671-74

16. Smith WS, Dowd CF, Johnston SC, et al. Neurotoxicity of intra-arterial papaverine preserved with chlorobutanol used for the treatment of cerebral vasospasm after aneurysmal subarachnoid hemorrhage. Stroke 2004;35:2518-22. Epub 2004 Oct 7

17. Sayama CM, Liu JK, Couldwell WT. Update on endovascular therapies for cerebral vasospasm induced by aneurysmal subarachnoid hemorrhage. $\mathrm{Neu}$ rosurg Focus 2006;21:E12
18. Babbitt DG, Perry JM, Forman MB. Intracoronary verapamil for reversal of refractory coronary vasospasm during percutaneous transluminal coronary angioplasty. J Am Coll Cardiol 1988;12:1377-81

19. Hunt WE, Hess RM. Surgical risk as related to time of intervention in the repair of intracranial aneurysms. J Neurosurg 1968;28:14-20

20. Fisher CM, Kistler JP, Davis JM. Relation of cerebral vasospasm to subarachnoid hemorrhage visualized by computerized tomographic scanning. Neurosurgery 1980;6:1-9

21. United Kingdom transient ischaemic attack (UK-TIA) aspirin trial: interim results-UK-TIA Study Group. BMJ (Clin Res Ed) 1988;296:316-20

22. Takayasu M, Bassett JE, Dacey RG Jr. Effects of calcium antagonists on intracerebral penetrating arterioles in rats. J Neurosurg 1988;69:104-09

23. Aralasmak A, Akyuz M, Ozkaynak C, et al. CT angiography and perfusion imaging in patients with subarachnoid hemorrhage: correlation of vasospasm to perfusion abnormality. Neuroradiology 2009;51:85-93

24. Wintermark M, Ko NU, Smith WS, et al. Vasospasm after subarachnoid hemorrhage: utility of perfusion CT and CT angiography on diagnosis and management. AJNR Am J Neuroradiol 2006;27:26-34

25. Hattingen E, Blasel S, Dettmann E, et al. Perfusion-weighted MRI to evaluate cerebral autoregulation in aneurysmal subarachnoid haemorrhage. Neuroradiology 2008;50:929-38. Epub 2008 Jun 17

26. Kassell NF, Peerless SJ, Durward QJ, et al. Treatment of ischemic deficits from vasospasm with intravascular volume expansion and induced arterial hypertension. Neurosurgery 1982;11:337-43

27. Solenski NJ, Haley EC Jr, Kassell NF, et al. Medical complications of aneurysmal subarachnoid hemorrhage: a report of the multicenter, cooperative aneurysm study-Participants of the Multicenter Cooperative Aneurysm Study. Crit Care Med 1995;23:1007-17

28. Eskridge JM, Song JK, Elliott JP, et al. Balloon angioplasty of the A1 segment of the anterior cerebral artery narrowed by vasospasm: technical note. J Neurosurg 1999;91:153-56

29. Terry A, Zipfel G, Milner E, et al. Safety and technical efficacy of over-the-wire balloons for the treatment of subarachnoid hemorrhage-induced cerebral vasospasm. Neurosurg Focus 2006;21:E14

30. Linskey ME, Horton JA, Rao GR, et al. Fatal rupture of the intracranial carotid artery during transluminal angioplasty for vasospasm induced by subarachnoid hemorrhage: case report. J Neurosurg 1991;74:985-90

31. Albanese E, Russo A, Quiroga M, et al. Ultrahigh-dose intraarterial infusion of verapamil through an indwelling microcatheter for medically refractory severe vasospasm: initial experience. J Neurosurg 2010;113:913-22

32. Feng L, Fitzsimmons BF, Young WL, et al. Intraarterially administered verapamil as adjunct therapy for cerebral vasospasm: safety and 2-year experience. AJNR Am J Neuroradiol 2002;23:1284-90

33. Keuskamp J, Murali R, Chao KH. High-dose intraarterial verapamil in the treatment of cerebral vasospasm after aneurysmal subarachnoid hemorrhage. J Neurosurg 2008;108:458-63

34. Mazumdar A, Rivet DJ, Derdeyn CP, et al. Effect of intraarterial verapamil on the diameter of vasospastic intracranial arteries in patients with cerebral vasospasm. Neurosurg Focus 2006;21:E15

35. Westhout FD, Nwagwu CI. Intra-arterial verapamil-induced seizures: case report and review of the literature. Surg Neurol 2007;67:483-86, discussion 486

36. Oskouian RJ Jr, Martin NA, Lee JH, et al. Multimodal quantitation of the effects of endovascular therapy for vasospasm on cerebral blood flow, transcranial Doppler ultrasonographic velocities, and cerebral artery diameters. Neurosurgery 2002;51:30-41, discussion 41-33

37. Zubkov YN, Nikiforov BM, Shustin VA. Balloon catheter technique for dilatation of constricted cerebral arteries after aneurysmal SAH. Acta Neurochir (Wien) 1984;70:65-79

38. Kobayashi $\mathrm{H}$, Ide $\mathrm{H}$, Aradachi $\mathrm{H}$, et al. Histological studies of intracranial vessels in primates following transluminal angioplasty for vasospasm. $\mathrm{J} \mathrm{Neu}$ rosurg 1993;78:481-86

39. Honma Y, Fujiwara T, Irie K, et al. Morphological changes in human cerebral arteries after percutaneous transluminal angioplasty for vasospasm caused by subarachnoid hemorrhage. Neurosurgery 1995;36:1073-80, discussion $1080-81$

40. Dominic JA, Bourne DW, Tan TG, et al. The pharmacology of verapamil. III. Pharmacokinetics in normal subjects after intravenous drug administration. J Cardiovasc Pharmacol 1981;3:25-38

41. Hop JW, Rinkel GJ, Algra A, et al. Case-fatality rates and functional outcome after subarachnoid hemorrhage: a systematic review. Stroke 1997;28:660-64

42. Molyneux AJ, Kerr RS, Yu LM, et al. International subarachnoid aneurysm trial (ISAT) of neurosurgical clipping versus endovascular coiling in 2143 patients with ruptured intracranial aneurysms: a randomised comparison of effects on survival, dependency, seizures, rebleeding, subgroups, and aneurysm occlusion. Lancet 2005;366:809-17

43. Komotar RJ, Zacharia BE, Otten ML, et al. Controversies in the endovascular management of cerebral vasospasm after intracranial aneurysm rupture and future directions for therapeutic approaches. Neurosurgery 2008;62:897-905, discussion 905-07 